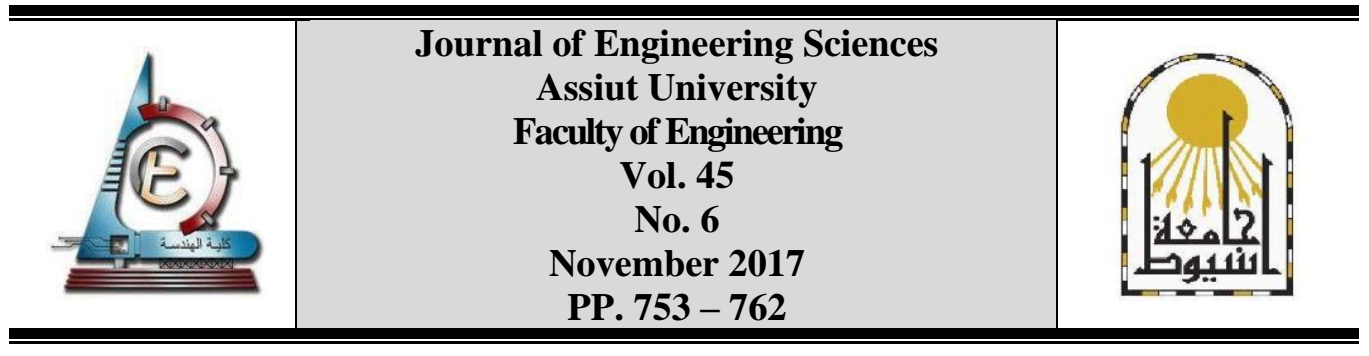

\title{
EFFECT OF VARIOUS ALUMINUM WASTE GRADATIONS ON LIQUID LIMIT AND UNDRAINED SHEAR STRENGTH BEHAVIOUR OF CLAY SOIL
}

\author{
Waleed Sulaiman MUSTAFA \\ Civil Engineering, Technical Institute of Bardarash, Duhok Polytechnic University, \\ Ministry of Higher Education/ Kurdistan Regional Governorate, Iraq
}

Received 15 August 2017; Accepted 17 September 2017

\begin{abstract}
This study presents the results of fall cone penetration tests conducted on clay and clay aluminum waste mixtures. The influence of aluminum waste (AW) gradations, which produced after cutting aluminum sections, on liquid limit and undrained shear strength of clay soil was checked throughout a series of tests. Three various particle gradations $(4.75-0.075 \mathrm{~mm}, 0.6-0.075$ $\mathrm{mm}$, and $0.425-0.3 \mathrm{~mm}$ ) of AW were added to low plasticity clay. The percentage of additive AW were $0 \%, 10 \%, 20 \%, 30 \%, 40 \%$ and $50 \%$. The results of clay aluminum waste (CAW) mixtures explained that there is a linear relationship between cone penetration and water content. Liquid limit and undrained shear strength reached their minimum values at $10 \%$ of AW of both gradations (4.75$0.075 \mathrm{~mm}$ and $0.6-0.075 \mathrm{~mm})$ and at $30 \%$ of $(0.425-0.3 \mathrm{~mm})$ AW gradation. By adding other percentages of AW, the amount of liquid limit and undrained shear strength were increased again. It was realized that the coarser the AW gradation the more the effect on liquid limit and undrained shear strength values. This may be due to the influence of larger particles of AW which made stronger connections between whole particles of AW and increased the resistance strength of the mixture against penetration. Also, a slight difference in both liquid limit and undrained shear strength values appeared when the gradation contains good amounts of same particle size.
\end{abstract}

Keywords: fall cone, clay, aluminum waste, liquid limit, undrained shear strength.

\section{Introduction}

Metal waste materials produced from the processes of metal industry which can be used as improvement materials. This study investigates the effect of adding aluminum waste (AW) material on the behaviour of clay soil. The strength and roughness that the aluminum waste particles have may lead to improve the engineering properties of clay soils. According to previous studies the availability of additional admixtures inside cohesive soils affects its strength and mechanical properties. [1] investigated the effect of waste nylon fibers on the mechanical behaviour of clay soil and concluded that the availability of fibers will cause an increase in amount of excess pore water pressure. [5] studied the shear strength of polypropylene fibers-reinforced clay soil and found that the shear strength of the mixture increased due to increasing in amount of cohesion and internal friction angle. 
Results of the tests obtained using a fall cone to determine liquid limit and undrained shear strength with respect to the change in amount of water content. Using fall cone for estimating liquid limit values has been studied by many researchers among them $[15,3,4$, 17, 18, 8 and 2]. Index properties of clay-admixture materials state that the liquid limit falls linearly with the clay content [13,10 and 14]. The fall cone technique considers a reliable method for observing the values of liquid limit and it's adopted as standard in many countries (e.g. British Standard Institute, 1991) since it can be readily used with the presence of granular materials which have a particle size greater than $0.425 \mathrm{~mm}$ which can be added into the testing container and does not prevent it to penetrate the soil mixtures.

From previous studies it appeared that aluminum waste materials have not been used as soil improvement materials. However, improving soil properties using waste metal deposits can be relatively considered as a new method in civil engineering works. This study aims at showing the effect of aluminum waste materials on the degree of improvement of clay soil depending on the results obtained from the fall cone device. During the laboratory work, many experimental tests have been conducted on the mixtures of clay and clay-aluminum wastes mixtures with different proportions of aluminum waste materials $(0 \%, 10 \%, 20 \%, 30 \%, 40 \%$ and $50 \%)$. Also, to investigate the effect of aluminum waste particle size distributions on the behaviour of clay soil, three different aluminum waste gradations are added during the experimental studies which are (4.75$0.075) \mathrm{mm},(0.6-0.0 .75) \mathrm{mm}$ and $(0.425-0.3) \mathrm{mm}$. Aluminum waste materials can be used in the construction of geotechnical structures such as highway projects. In such civil engineering projects, the construction process can be done by mixing a required amount of aluminum waste materials with subgrade (clay soil) by plowing the subgrade and mixing with aluminum waste ahead of the compaction and road construction.

\section{Experimental study}

\subsection{Materials}

During the experimental works clay and waste aluminum were used to prepare the testing samples. Clay used in the laboratory works can be considered as a low to high plasticity clay.

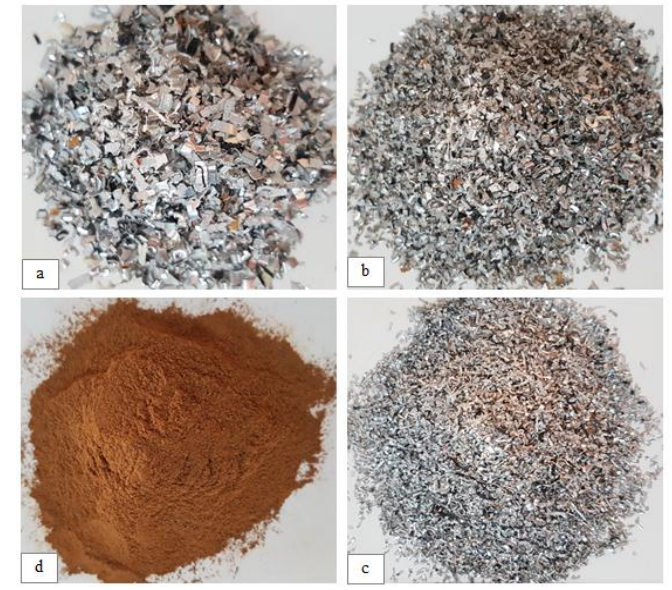

Fig. 1. Used clay and waste aluminum gradations, (a) Gradation 1 (4.75-0.075 mm), (b) Gradation2 (0.6-0.075 mm), (c) Gradation3 (0.425-0.3 mm), (d) Pure clay. 


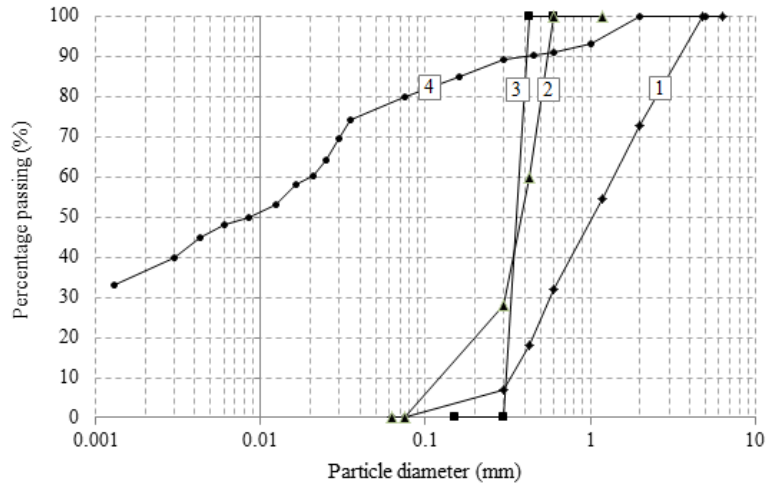

Fig.2. Particle size distributions for clay and aluminum wastes used during the experimental study. (1) Gradation 1 (4.75-0.075 mm), (2) Gradation 2 (0.6-0.075 mm), (3) Gradation $3(0.425-0.3 \mathrm{~mm})$, (4) Clayey soil.

It is observed that the clay soil has liquid and plastic limits equal to 49.5 and 23 , respectively. The specific gravity of the clay soil is equal to 2.62. Also, the maximum unit weight and optimum water content of the clay soil is equal to $\left(15.68 \mathrm{kN} / \mathrm{m}^{3}\right.$ and $\left.22.1 \%\right)$ respectively. Particle size distribution of the clay soil is as shown in Figure (2). Fall cone tests were conducted to estimate the liquid limit and undrained shear strength of the clay soil.

Aluminum waste material is collected from Bardarash District, Duhok Province, Kurdistan Region/Iraq. It produced after cutting aluminum sections at local factories to prepare some special kitchen and other houses requirement parts.

Three different gradations of aluminum waste are used to form the clay aluminum waste mixtures. Particle size distributions of all gradations of aluminum waste are as shown in Figure (2). The specific gravity of aluminum waste is equal to 1.7. The mixtures of clay aluminum waste are tested by using distilled water as a pore fluid to avoid the effect of ions which may be available in tap water during laboratory works.

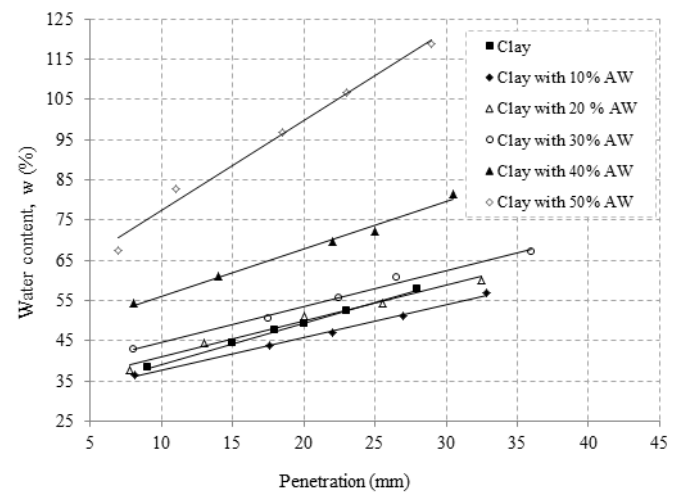

Fig. 3. Variation of cone penetration with water content for the clay with $4.75-0.075 \mathrm{~mm}$ (Gradation 1) AW.

The three gradations of aluminum waste have a size limit ranging between $4.75 \mathrm{~mm}$ to $0.75 \mathrm{~mm}$ (Gradation 1), $0.6 \mathrm{~mm}$ to $0.075 \mathrm{~mm}$ (Gradation 2), and $0.425 \mathrm{~mm}$ to $0.3 \mathrm{~mm}$ (Gradation 3). The gradations of aluminum waste are selected to assess their effects on the behavior of clay soil and to get relatively uniform specimens for visual classification purposes. 


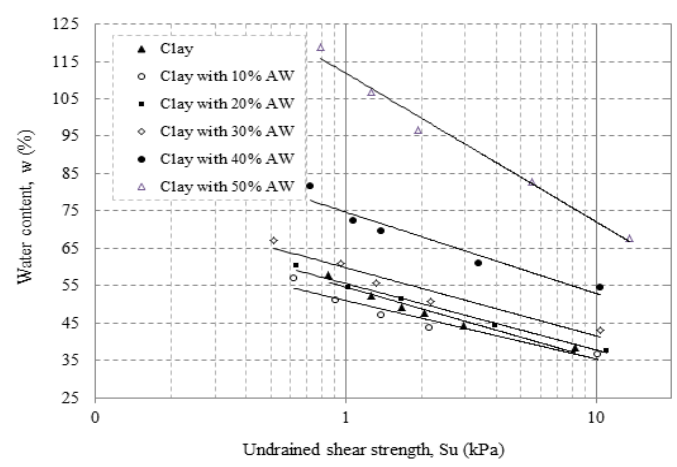

Fig. 4. Relationship between undrained shear strength and water content for the clay with 4.75$0.075 \mathrm{~mm}$ (Gradation 1) AW.

\subsection{Testing apparatus and experimental procedure}

Fall cone tests are conducted by depending on fall cone apparatus according to British Standard (BS1377:Part2:1990). The fall cone was made by Wykeham Farrance, with $30^{\circ}$ cone and weighing $0.785 \mathrm{~N}$. The sample container dimensions of the fall cone apparatus are $55 \mathrm{~mm}$ in diameter and $40 \mathrm{~mm}$ in height.

For studying the index properties of samples tested, it is so important to maintain the consistency among the samples prepared for testing. Therefore, great care should be considered to obtain the required specimens during the preparation process for all samples which will be tested. The used preparation techniques for all mixtures are the same. The mixtures of clay aluminum waste are prepared by depending on dry weight of oven dried materials after setting oven temperature on $105^{\circ} \mathrm{C}$ for 24 hours. The required amounts of clay and aluminum waste are weighted then mixed in dry conditions manually using hands to get homogenous mixtures.

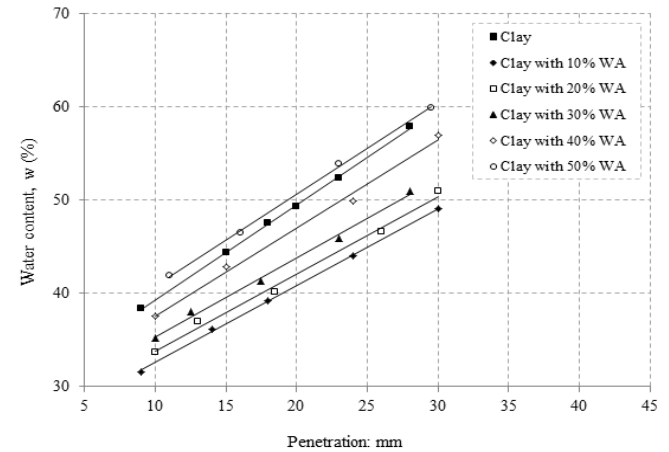

Fig. 5. Variation of cone penetration with water content for the clay with $0.6-0.075 \mathrm{~mm}$ (Gradation 2) AW.

The mixtures are mixed with distilled water to the required amount of water content and cured for $24 \mathrm{~h}$ by covering the sample container with plastic bag to allow for complete water saturation before testing. A special spatula is used to place the prepared soil mixtures into the fall cone cup without trapping air inside by shaking the cup after putting some amount of the soil mixture inside it. The straight edge with the beveled side is used to level the excess soil from the surface of the cup till having a smooth surface.

The soil sample is assembled on the device in such a way that its surface being in contact with the cone. The depth of the penetration was checked after five seconds. Many trials are performed to investigate the repeatability of the testing results. To evaluate the amount of water 
content, a part of the same specimen is oven dried at $105^{\circ} \mathrm{C}$ temperature. The testing steps are repeated for all proportions of the soil mixtures at various amounts of water contents.

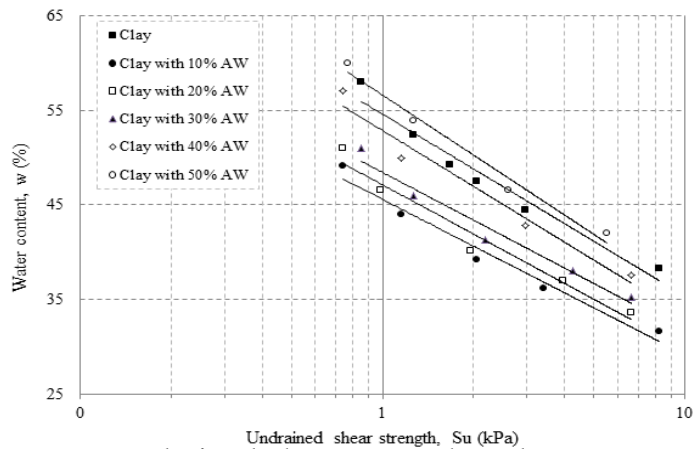

Fig. 6. Relationship between undrained shear strength and water content for the clay with $0.6-$ $0.075 \mathrm{~mm}$ (Gradation 2) AW.

\section{Results and discussions}

\subsection{Liquid limit properties}

The relationship between depth of penetration of the fall cone with the amount of water content for mixtures of aluminum waste gradation (4.75-0.75) $\mathrm{mm}$ for each percent are shown in Figure (3). From the figure, it can be noticed that there is an approximate linear relationship between cone penetration and amount of water content. The easiest way of interpreting these results is to observe the amount of water content of each clay aluminum waste mixture for the cone penetration would be exactly $20 \mathrm{~mm}$. The value of liquid limit (LL) for pure clay is about 49.5 . By adding just $10 \%$ of aluminum waste, liquid limit value decreased. Same result is found by many previous researchers [6] after they added various proportions of sandy soil to clay soil. After continuously increasing the amounts of aluminum waste, liquid limit values increased again. This is because of the significant influence of high aluminum waste content on the mixture behaviour which may be due to the interaction between the clay and aluminum waste particles. This interaction is noticeable because of the sharp edges of the aluminum waste particles, the large difference between the unit weights of aluminum waste and clay, as it is previously noticed in the material properties. As a result, more water content is needed to decrease the interaction between the aluminum waste and clay particles and to reach a required liquid limit value for each mixture.

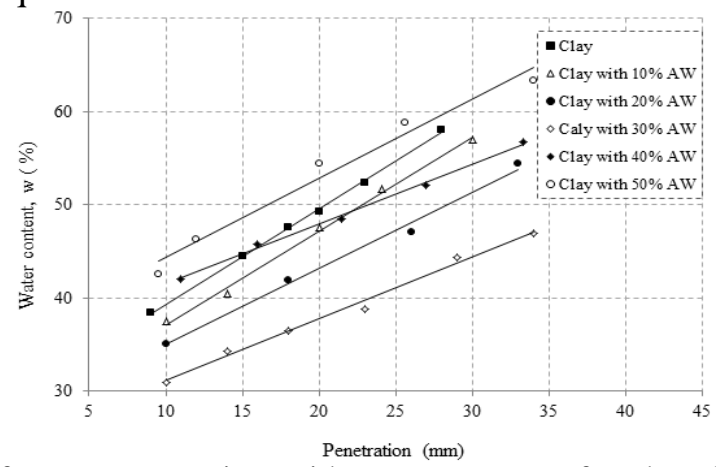

Fig. 7. Variation of cone penetration with water content for the clay with $0.425-0.3 \mathrm{~mm}$ (Gradation 3) AW.

Two more gradations of aluminum waste, with simple difference in particle size, are added to clay soil (Gradation 2 and 3). The liquid limit behaviour of clay aluminum waste 
mixtures of both gradations is illustrated in Figures (5) and (7). In both conditions, the liquid limit values are significantly affected by adding the aluminum waste. Minimum values of liquid limit are observed after adding $10 \%$ of waste gradation $(0.6-0.075 \mathrm{~mm})$ and $30 \%$ of gradation $(0.425-0.3 \mathrm{~mm})$. Slight changes in the liquid limit values are noticed after continuously increasing percentages of aluminum waste as it is noticed in Figure (8).

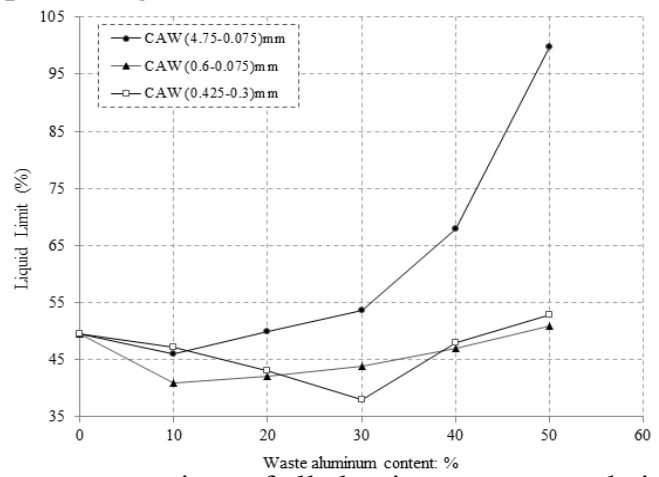

Fig. 8. Relationship between proportions of all aluminum waste gradations with liquid limit values.

In addition, the effect of particle size of different aluminum waste gradations on the behaviour of liquid limit values is shown in Figure (8). The figure shows that when aluminum waste contains much larger particle sizes ( 4.75 to 0.75$) \mathrm{mm}$, the change interval in liquid limit value is much more noticeable for smaller particle sizes $(0.6$ to $0.75 \mathrm{~mm}$ and 0.425 to $0.3 \mathrm{~mm}$ ). The author thought that this is probably because larger particle size of aluminum waste controls the soil media by introducing stronger connections between individual particles and the clay media. Therefore, higher water contents are needed to soften the connections and reach the required depth of penetration.

Also to define an apparent liquid limit for clay matrix only at each clay aluminum waste mixture, Equation (1) can be used by converting the water content $(w)$ into the clay water content $\left(\mathrm{w}_{\mathrm{c}}\right)$.

$$
w_{c}=\frac{m_{c}}{m_{w}}
$$

Where, $\left(\mathrm{w}_{\mathrm{c}}\right)$ is water content of the clay only, $\left(\mathrm{m}_{\mathrm{w}}, \mathrm{m}_{\mathrm{c}}\right.$ and $\left.\mathrm{w}\right)$ are mass of water, mass of clay, and water content for the clay aluminum waste mixture, respectively. By depending on Equation (1) the result of apparent liquid limit is drawn as appeared in Figure (9).

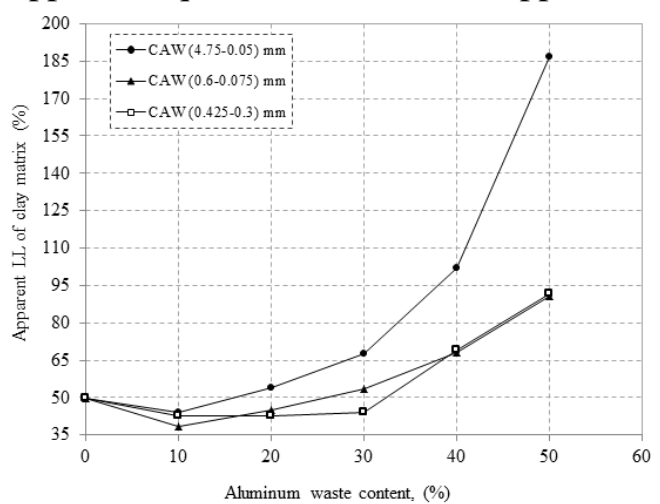

Fig. 9. Apparent liquid limit of clay matrix only as a function of aluminum waste content of all gradations.

It is observed from Figure (9) that the apparent liquid limit of clay matrix only is approximately decreased by $(11.3 \%$ and $14.3 \%)$ after adding $(10 \%)$ of aluminum waste of 
Waleed sulaiman mustafa, effect of various aluminum waste gradations on liquid limit and ........

both gradations $((4.75-0.075) \mathrm{mm}$ and $(0.425-0.3) \mathrm{mm})$ respectively and by $(22.2 \%)$ of $(0.6-$ $0.075) \mathrm{mm}$ aluminum waste gradation. The reason behind this behaviour of clay matrix only is may be because the mixture lost its homogeneity after adding aluminum waste materials which led to need less amount of water content to reach the designated depth.

After continuously increasing the amount of aluminum waste to the clay soil the apparent liquid limit increased again by about (277.7\%) of (4.75-0.075) $\mathrm{mm}$ aluminum waste gradation and by $(83 \%$ and $85 \%)$ of other gradations $((0.425-0.3) \mathrm{mm}$ and $(0.6-0.75)$ $\mathrm{mm}$ ) respectively at $(50 \%)$ of aluminum waste content. The increase in the apparent liquid limit of clay matrix only is related to the effect of aluminum waste particles against cone penetration which led to controlling the behavior of clay aluminum waste mixture. At the end, the mixture needed much more amount of water content to separate the particles from each other and reach the required depth of water penetration. It is also noticed that the amount of increase in the apparent liquid limit was much more when the gradation of aluminum waste grains contain larger particle size. This may be because the larger particles of aluminum waste means that the gradation contains longer particles also. The longer particles made a stronger connection between the whole particles of aluminum waste, so much more amount of water content needed to separate them from each other.

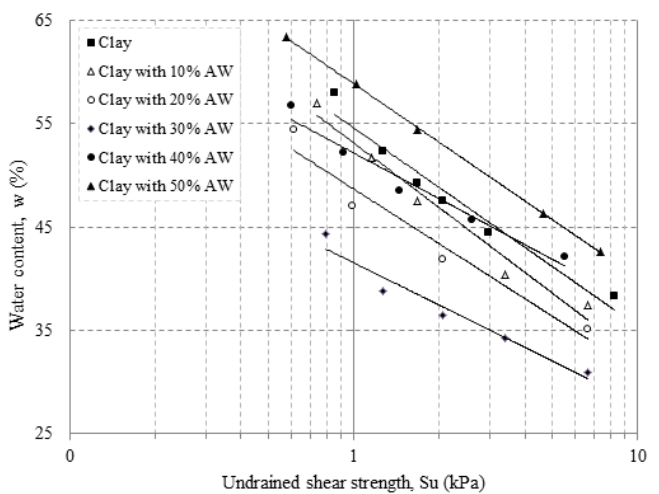

Fig. 10. Relationship between undrained shear strength and water content for the clay with $0.425-0.3 \mathrm{~mm}$ (Gradation 3) WA.

\subsection{Undrained shear strength properties}

It has been presented before [7] that the fall cone do not only used to determine the values of liquid limits because of the reaction recorded by cohesive soil against penetration represent the strength and degree of compressibility of that soil. [3] observed that the amount of undrained shear strength $(\mathrm{Su})$ is a function of cone mass $(\mathrm{m})$ and distance of penetration (d), as shown in Equation (2):

$$
S_{u}=k \frac{m g}{d^{2}}
$$

Where, $(\mathrm{g})$ is the acceleration of gravity, and $(\mathrm{k})$ is a constant, which varies according to the apex angle of the cone and is observed to be 0.85 for an angle of $30^{\circ}$ British cone [18]. Therefore, the obtained result which is shown in Figure (3) can be correlated with the undrained shear strength and the amount of water content of the clay-aluminum waste mixtures as shown in Figure (4). As can be seen from Figure (4), the undrained shear strength of the clay aluminum waste mixtures is primarily controlled by the water content of the clay matrix (wc), which was calculated using Equation (1). This means that amount 
of change in the undrained shear strength values can be estimated depending on changes in the amount of water content because the fall cone device is a strength measuring device.

Clay soil can be considered a complex matrix after adding different components as explained by many previous researchers [11, 9, 16 and 12]. [6] investigated that the internal resistance strength of a complex soil matrix consisting of crushed quartz and various clay minerals depends on the relative volume of clay minerals and quartz minerals. Same thing happened to clay aluminum waste mixtures after adding $10 \%$ and $30 \%$ of aluminum waste to clay soil according to type of gradations as illustrated in Figures (4), (6) and (8). This led to reduction in volume of clay particles which resulted in separation of its particles from each other. As a result, the mixture lost its homogeneity and the undrained shear strength decreased. Therefore the amount of water content of the clay matrix was decreased.

On the other hand, an increase in the undrained shear strength is noticed after adding more proportions of aluminum waste to the clay soil. The higher proportions of aluminum waste led to larger change in the volume which is occupied by its particles having rough surface edges. The roughness of waste particles generates a very strong interlocking force to the composite mixture. As a result, the composite mixture is controlled by aluminum waste particles distributed inside clay media along with the aluminum particles stucked with each other. At the end, the resistance of the mixture against penetration increased and resulted in needing more water content to penetrate the soil mixture and separate the particles from each other and reach the designated depth. Figures (4), (6) and (8) also show that when the used gradation contains large particle sizes, the changing interval in amount of water content was much bigger than when smaller particle size which means a higher values of undrained shear strength. This is because larger and consequently longer particles worked as a very small reinforcing element and led to increasing the resistance of the mixture therefore a higher amount of water content was needed.

\section{Conclusions}

In this study the behaviour of liquid limit and undrained shear strength of clay aluminum waste mixtures are presented depending on fall cone apparatus. From the test results the following points are concluded:

1- An approximately linear relationship between the cone penetration and the water content of all mix percentages and aluminum waste gradations.

2- Values of liquid limit and amount undrained shear strength decreased and reached its lowest level at various percentages of aluminum waste gradations, $10 \%$ for (4.75$0.075 \mathrm{~mm}$ and $0.6-0.75 \mathrm{~mm})$ and $30 \%$ for $(0.425-0.3 \mathrm{~mm})$, then their values increased again for coarser gradation.

3- A slight difference in the behaviour of both liquid limit and undrained shear strength values is noticed when the gradation contained somewhat uniform particle gradation.

4- It is revealed that when the gradation of aluminum waste, which added to clay soil contain much larger particle sizes, the rate of change in both liquid limit and undrained shear strength values are more pronounced than the smaller particles.

5- It is observed that the apparent liquid limit of clay matrix only is approximately decreased by $(11.3 \%$ and $14.3 \%)$ after adding $(10 \%)$ of aluminum waste of both gradations $((4.75-0.075) \mathrm{mm}$ and $(0.425-0.3) \mathrm{mm})$ respectively and by $(22.2 \%)$ of (0.6-0.075) $\mathrm{mm}$ aluminum waste gradation. 
Waleed sulaiman mustafa, effect of various aluminum waste gradations on liquid limit and ........

6- By continuously increasing the amount of aluminum waste to the clay soil the apparent liquid limit increased again by about $(277.7 \%)$ of $(4.75-0.075) \mathrm{mm}$ aluminum waste gradation and by $(85 \%$ and $83 \%)$ of other gradations $((0.6-0.75)$ $\mathrm{mm}$ and $(0.425-0.3) \mathrm{mm})$ respectively at $(50 \%)$ of aluminum waste content.

Acknowledgments

The author would like to thank Mr. Hussain Shigaly, Mr. Hashyar Muhammed Ameen and Mr. Sardar Fadel Qasim for their invaluable help.

\section{REFERENCES}

[1] Estabragh, A.R., Bordbar, A.T., and Javadi, A.A. 2011. Mechanical Behavior of a Clay Soil Reinforced with Nylon Fibers, Geotechnical and Geological Engineering, 29, 899-908.

[2] Feng, T.W., 2000. Fall-cone penetration and water content relationship of clays Geotechnique 50 (2), 181-187.

[3] Hansbo, S., 1957. A new approach to the determination of the shear strength of clay by the fall-cone test. R. Swedish Geotech. Inst. Proc. No. 14.

[4] Houlsby, G.T., 1982. Theoretical analysis of the fall-cone test. Geotechnique 32 (2), 111-118.

[5] Jiang, H., Cai, Y., and Liu, J., 2010. Engineering properties of soils reinforced by short discrete polypropylene fiber, Journal of Materials in Civil Engineering (ASCE), 22(12), 1315.

[6] Kenny, T.C., 1977. Residual strength of mineral mixture. Proc. 9th International Conference of Soil Mechanics and Foundation Engineering, pp. 155-160.

[7] Kumar, G.V., Wood, D.M., 1999. Fall cone and compression tests on clay-gravel mixtures Geotechnique 49 (6), 727-739.

[8] Leroueil, S., Le Bihan, J.P., 1996. Liquid limits and fall cones. Can. Geotech. J. 33 (5), 793-798.

[9] Monkul, M.M., Ozden, G., 2007. Compressional behavior of clayey sand and transition fines content. Eng. Geol. 89, 195-205.

[10] Nagaraj, T.S., Murthy, B.R.S., Bindumadhava, T.S., 1987. Liquid limit determination further simplified. Geotech. Test. J. 12 (4), 302-307.

[11] Ni, Q., Tan, T.S., Dasari, G.R., Hight, D.W., 2004. Contribution of fines to the compressive strength of mixed soils. Geotechnique 54 (9), 561-569.

[12] Rahman, M.M., Lo, S.R., 2008. The prediction of equivalent granular steady state line of loose sand with fines. Geomech. Geoeng. 3 (3), 179-190.

[13] Seed, H.B., Woodward, R.J., Lundgren, R., 1964. Fundamental aspects of the Atterberg limits. J. Soil Mech. Found. Div. ASCE 90 (SM6), 75-105.

[14] Tan, T.S., Goh, T.C., Karunaratne, G.P., Lee, S.L., 1994. Shear strength of very soft claysand mixtures. Geotech. Test. J. 17 (1), 27-34.

[15] Terzaghi, K., 1927. Determination of consistency of soils by means of penetration tests Public Roads 7 (12), 240-247.

[16] Thevanayagam, S., 1998. Effect of fines on confining stress on undrained shear strength of silty sands. J. Geotech. Geoenviron. Eng. ASCE 124 (6), 479-491.

[17] Wood, D.M., 1982. Cone penetrometer and liquid limit. Geotechnique 32 (2), 152-157.

[18] Wood, D.M., 1985. Some fall cone tests. Geotechnique 35 (1), 64-68. 


\section{تأثير تدرجات مختلفة من بقايا الألمنيوم على سلوك حد السيولة ومقاومة القص غير المتصرف للتربة الطينية}

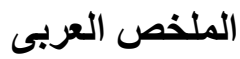

تقدم هذه الدراسة نتائج اختبارات اختراق المخروط الساقط التي أجريت على الطئ الطين ومزيج الطين مع بقايا

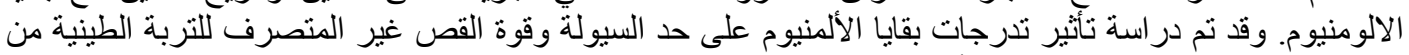

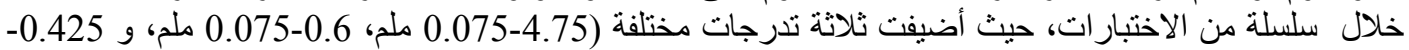

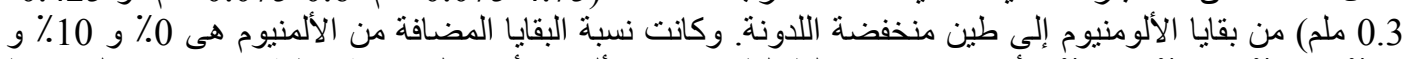

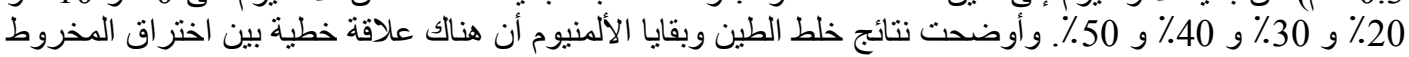

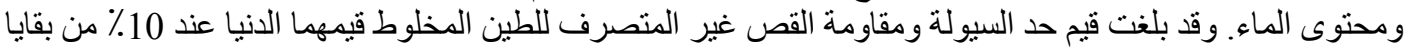

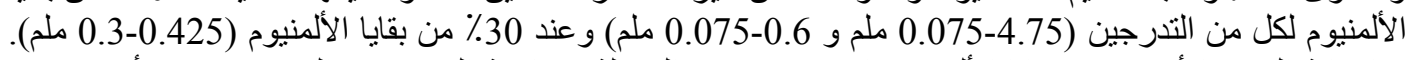

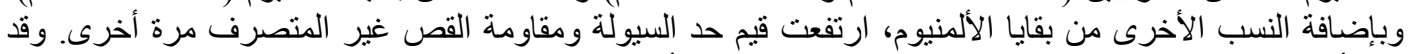

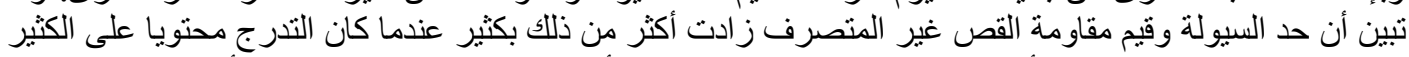

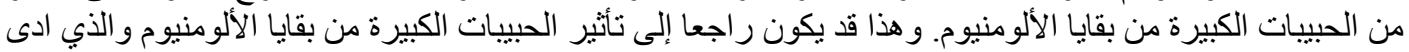

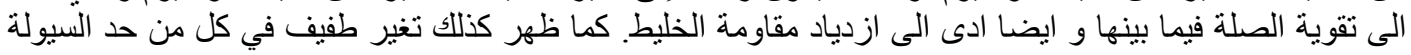
وقيم مقاومة القص غير المتصرف عندما كان التدرج محنويا على كميات كبيرة من الحبيبات ذوي الخيط الحجم نفسها. الكلمات المفتاحيةّ: المخروط الساقط، طين، يقايا الالومنيوم، الحد السائل، قوة القص غير النافذة. 